\title{
Effects of McKenzie Approach and Kinesio Taping Technique in Individuals with Mechanical Low Back Pain: A Comparative Study
}

\author{
Manikandan A 1, David V Samuel 2, Mohammed Qasheesh ${ }^{3}$, Senthilkumar \\ Cennappan Bose ${ }^{*}$.
}

${ }^{1}$ Physiotherapy Division, Rehab, Coimbatore, Tamilnadu, India.

${ }^{2}$ Physiotherapy Division, Government Hospital, Pudukkottai, Tamilnadu, India.

${ }^{3}$ Department of Physical Therapy, College of Applied Medical Sciences, Jazan University, Jazan, Kingdom of Saudi Arabia.

${ }^{*}$ Department of Physical Therapy, University College of AlArda, Jazan University, Jazan, Kingdom of Saudi Arabia.

\section{ABSTRACT}

Objective of this study is to compare the effects of McKenzie approach and kinesio taping technique in individuals with mechanical low back pain. Materials and Methods used are, Quasi experimental study design in the study setting of Department of Physiotherapy, Kovai Medical Centre and Hospital, Coimbatore with the sample of the 20 Patients with Mechanical low back pain who met the inclusion criteria were selected for the study. They were Grouped in A and B with each of 10 Patients. Among the patients, Group A received McKenzie approach and Group B received Kinesio taping. Patients were measured for Pain status by Visual Analogue Scale, Functional ability by Modified Oswestry Disability Index Scale. Results of the data were analyzed using paired, and independent " $t$ tests at $5 \%$ level of significance. Even though, there was a significant improvement in both the groups, the McKenzie approach group showed a greater improvement when compared to Kinesio taping technique group. We conclude that McKenzie approach is more effective therapy for mechanical low back pain patients.

KEY WORDS: Mechanical low back pain, McKenzie approach, Kinesio taping technique.

Address for correspondence: : Dr.Senthilkumar Cennappan Bose, Department of Physical Therapy, University College of AlArda, Jazan University, Kingdom of Saudi Arabia.

Mob: +966-531814506. E-Mail: Sbose@jazanu.edu.sa

\begin{tabular}{|c|c|c|c|}
\hline Access this Article online & \multicolumn{3}{|c|}{ Journal Information } \\
\hline Quick Response code & \multicolumn{3}{|c|}{$\begin{array}{l}\text { International Journal of Physiotherapy and Research } \\
\text { ISSN (E) 2321-1822 I ISSN (P) 2321-8975 } \\
\text { https://www.ijmhr.org/ijpr.html } \\
\text { DOI-Prefix: https://dx.doi.org/10.16965/ijpr }\end{array}$} \\
\hline & \multicolumn{3}{|c|}{ Article Information } \\
\hline DOI: 10.16965/ijpr.2021.119 & $\begin{array}{l}\text { Received: } 25 \text { Feb } 2021 \\
\text { Peer Review: } 26 \text { Feb } 2021 \\
\text { Revised: None }\end{array}$ & $\begin{array}{l}\text { Accepted: } 04 \text { Apr } \\
\text { Published (O): } 11 \\
\text { Published (P): } 11\end{array}$ & $\begin{array}{l}21 \\
2021\end{array}$ \\
\hline
\end{tabular}

\section{INTRODUCTION}

Low back pain with a life time prevalence of approximately $60-80 \%$ is recognized internationally as a major health, social and economic burden [1].

Mechanical low back pain is one of the most common problems in modern society. It causes major economic problems in industrialized nations. It accounts for the second leading cause of absenteeism from work [2].

Most back pain presenting in general practice is due to the dysfunction of element of mobile segment - that is, the two apophyseal joints, the ligamentous and muscular attachments. This problem often referred as mechanical pain, a general term which covers 
both radicular and non-radicular pain, mainly includes dysfunction of the joint of the pain [3].

Mechanical low back pain is described as a musculoskeletal pain which varies with physical activities and not involving root compression or series of spinal disease [4].

Bed rest is considered to be an effective management of acute low back pain. There is strong evidence that supports bed rest greater than two days is not effective in the treatment of acute low back pain. Restriction of activity is impressive for recovery from mechanical low back pain.

The sedentary nature of modern existence and lack of physical fitness makes humans so liable to back pain. The cause of lower spine being so commonly affected could be due to inherent skeletal abnormalities, poor posture, inability of lumbar spine musculature to control movements and protect against injury. Weakness of lumbar spine muscles has been highlighted as a potential factor in the etiology of back pain.

The McKenzie approach is popular among physiotherapists as a management for spinal pain [5].

It is said to be a progression of mechanical forces applied by or to a patient in such a way that a minimal amount is utilized to effect a therapeutic change in the presenting mechanical syndrome [6].

McKenzie approach is a popular method for Mechanical low back pain. The McKenzie approaches are believed to improve functional abilities and reduce pain.

Kinesio Taping is another treatment approach used by physiotherapist to treat back pain Kinesio taping differs from normal traditional taping in the sense that it is elastic and can be stretched to $140 \%$ of its original length before being applied. Unlike the traditional white athletic tape, it provides a constant pulling (shear) force to the skin over which it is applied. The fabric is air permeable and water resistant and can be worn for repetitive days. Kinesio tape is currently being used immediately following injury and during the rehabilitation process $[7,8]$.
Mechanical low back pain patients are usually managed by conventional physiotherapy management which includes pain relieving modalities, stretching exercises for the spinal muscles and patient education.

Abundant studies were done on the effect of McKenzie approach but only few studies reported the benefits of McKenzie approach.

Kinesio taping is used for the management of mechanical low back pain. Many studies of Kinesio taping carried out for areas other than the back, only few studies reported the benefits of Kinesio taping on Mechanical low back pain.

Need for the Study: A wide range of population with mechanical low back pain are being affected by functional deficits, which disturb the patient's work related activities and psychological status.

Mechanical low back pain patients are usually treated by physiotherapy modalities, stretching exercises for the spinal muscles and patient education. New concept of treatment is now carried out in western countries to give better effects in treating patients with mechanical low back pain. But it is not popular in India, even though there are physiotherapists practicing manual therapy.

However, in India, there is a need for more evidence based research in the clinical setups to substantiate whether the interventions like McKenzie approach and Kinesio Taping technique will be beneficial.

This study tends to contrast the effects of McKenzie approach and Kinesio Taping technique in individuals with Mechanical low back pain.

Aim: To compare the effects of McKenzie approach and Kinesio Taping technique in individuals with Mechanical low back pain.

\section{Objectives:}

- To find out the effect of McKenzie approach on level of pain in individuals with Mechanical low back pain.

- To find out the effect of McKenzie approach on functional abilities of individuals with Mechanical low back pain.

- To find out the effect of Kinesio Taping 
technique on level of pain in individuals with Mechanical low back pain.

- To find out the effect of Kinesio Taping technique on functional abilities in individuals with Mechanical low back pain.

To compare the effects of McKenzie approach and Kinesio Taping technique in individuals with Mechanical low back pain.

\section{MATERIALS AND METHODOLOGY}

Study Design: Quasi experimental study design.

Study Population: Mechanical low back pain individuals

\section{Inclusion Criteria:}

Age: 20-40years, Male subjects, Mechanical low back pain-Dysfunctional syndrome, Physician diagnosis.

\section{Exclusion Criteria:}

Subjects with radiating pain such as Sciatica, Disc prolapse, recent history of fall, history of spinal Fracture, lumbar canal stenosis, tumour of spine, infection of spine, inflammatory disease of spine. - Like Ankylosing spondylitis, structural deformities such as kyphosis, scoliosis and Spondylolisthesis, cardiovascular problems and neurological problems

Sample Size: 20 Patients with Mechanical low back pain who met the inclusion criteria were selected for the study.

GROUP- A: 10 Patients

GROUP- B: 10 Patients

\section{Sampling Technique: Convenient sampling}

Study Setting: Department of physiotherapy, Kovai medical center and hospital, Coimbatore.

\section{Null Hypothesis:}

H01- There is no significant improvement on level of pain in individuals with Mechanical low back pain using McKenzie approach.

H02- There is no significant improvement on functional abilities in individuals with $\mathrm{Me}$ chanical low back pain using McKenzie approach.

H03- There is no significant improvement on level of pain in individuals with Mechanical low back pain using Kinesio Taping technique.
H04- There is no significant improvement on functional abilities in individuals with Mechanical low back pain using Kinesio Taping technique.

H05-There is no significant difference between McKenzie approach and Kinesio Taping technique in individuals with Mechanical low back pain.

Study Method: The study duration was 4 weeks. 20 Subjects who fulfils the inclusion criteria were assigned into two groups of 10 each. As group $A$, who received McKenzie approach and group $B$, who received Kinesio Taping.

Pre-test scores using VAS, and Modified Oswestry Disability Index Scale taken prior to the treatment protocol post test scores were taken after 4 weeks using the same.

\section{Treatment Procedure:}

Group- A: McKenzie Exercises (Frequency- 2 times a day, Repetition- 10 times, Rest interval- 5 minutes, 3 Session per week).

\section{Extension in Prone Lying:}

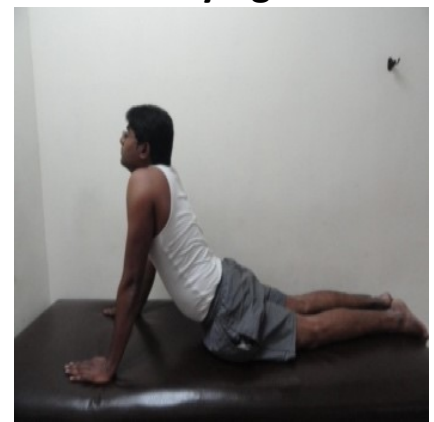

Patient was asked to lie in prone with arms beside the body and head turned to one side and maintain the position for 4-5 minutes.

In the same position, the patient was asked to place the elbows under the shoulders so that the patient lean on their forearms and maintain the position for 5 minutes.

Then the patient was advised to extend their elbows in the above position and push the top half of their body as far as the pain permits. The patient held the position for a second or two and then comes back to the starting position. This was done ten times per session.

\section{Extension in Standing:}

The patient was asked to stand upright with feet slightly apart, hands placed at the back 
so that the fingers are pointed backward and the thumbs forward. The patient bends backward at the waist as far as they can keeping the knees straight, maintaining this position for a second or two and return to the starting position.

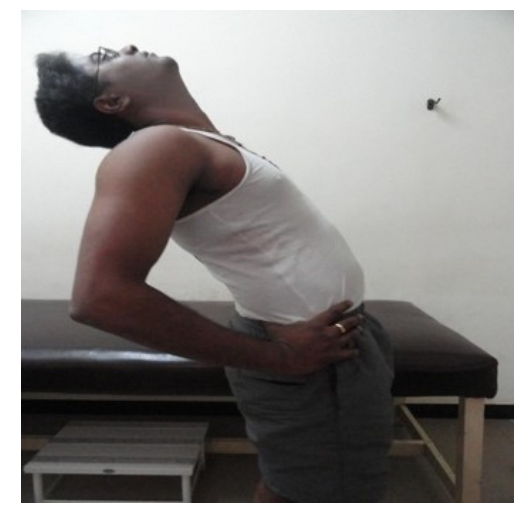

Flexion in Supine Lying:

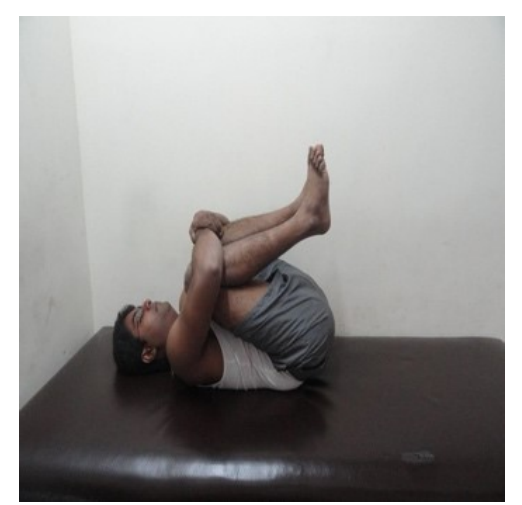

The patient was asked to lie supine with knees bent and foot placed on the couch. From this position the patient brings both the knees towards the chest and gently but firmly pulls the knees with hands towards the chest till pain permits. The patient maintains this position for 1-2 seconds and returns to starting position

Flexion in Sitting:

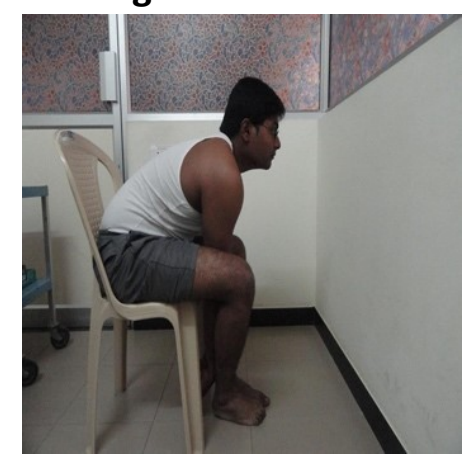

Patient sat on the edge of a chair with knees and feet well apart and hands resting in between legs touching the ground. From this position the patient bends forward and returns back.

\section{Standing and Side Gliding:}

The Patient was asked to stand with the feet approximately at shoulder level. McKenzie prefers the patient to perform a side-gliding movement while standing instead of lateral bending. This movement is done by instructing the patient to move the pelvis and trunk to the opposite direction while maintaining the shoulders level in the horizontal plane. It should be repeated to the right and left and compare the degree and quality of movement. Patients may try to increase the motion by lifting their lower extremity off the floor and raising their hip. This is limited by stabilizing the pelvis with your arm as the patient performs the movement testing.

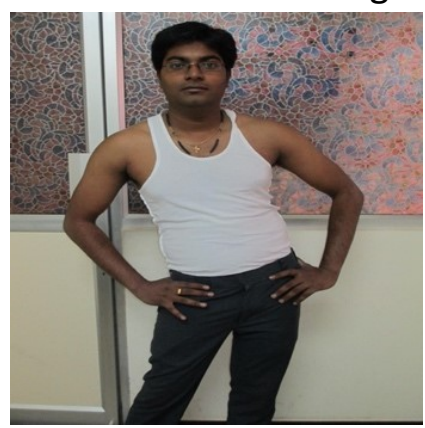

Group-B: Kinesio Taping: Three sessions per week

\section{Procedure:}

The patient was asked to bend forward to stretch back muscles. Apply " $Y$ " strip lightly above the tailbone and extend up along each side of the spine, with very little stretch.

Tear paper backing at middle of " $Y$ " strip. Still bent forward, add light to moderate stretch and place the center of the tape over strained area.

Lay down ends with no stretch

Space tape is applied over the " $Y$ " strip in a star like form.

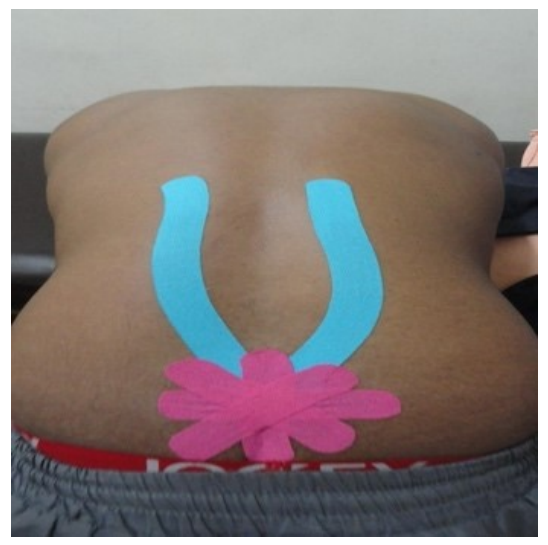


Outcome Measures: Pain status and Functional abilities

Measurement Tools: Visual Analogue Scale, Modified Oswestry Disability Index Scale

Statistical Analysis: Pre-test and post-test values of the study were collected and assessed for variation in improvement and their results was analysed using independent ' $\mathrm{t}$ ' test and paired ' $\mathrm{t}$ ' test.

\section{DATA ANALYSIS AND RESULTS}

\section{Modified Oswestry Disability Index Scale:}

\section{Paired ' $\mathrm{t}$ ' Test:}

\section{Group A (Pre-test and Post-test):}

' $\mathrm{t}$ ' test analysis within the group $A$ shows that there is significant improvement in functional abilities in individuals with Mechanical Low Back Pain, since the calculated ' $\mathrm{t}$ ' value 15.1065 is greater than the table ' $\mathrm{t}$ ' value 2.2621 at the $5 \%$ level of significance $(p<0.05)$, the null hypothesis is rejected.

\section{Group B (Pre-test and Post-test):}

' $\mathrm{t}$ ' test analysis within the group $B$ shows that there is significant improvement in functional abilities in individuals with Mechanical Low Back Pain, since the calculated ' $t$ ' value 14.1623 is greater than the table ' $\mathrm{t}$ ' value 2.2621 at the $5 \%$ level of significance $(p<0.05)$, the null hypothesis is rejected.

\section{Independent ' $t$ ' Test:}

\section{Pre-test Values (Group -A and Group-B):}

' $\mathrm{t}$ ' test analysis for the pre-test values of group A and group B for functional abilities is 0.5148 , which is less than the table ' $\mathrm{t}$ ' value 2.1009 at $5 \%$ level of significance, null hypothesis is accepted. It shows there is no significant difference in baseline value regarding functional abilities between the two groups.

\section{Post-test Values (Group -A and Group-B):}

' $\mathrm{t}$ ' test analysis for the post-test values of group $A$ and group $B$ for functional abilities is 2.2228 , which is greater than the table ' $\mathrm{t}$ ' value 2.1009 at $5 \%$ level of significance, null hypothesis is rejected. Hence the individuals treated with McKenzie approach have shown greater improvement than the individuals given taping.

\section{Visual Analogue Scale:}

Paired ' $\mathrm{t}$ ' Test:

\section{Group A (Pre-test and Post-test):}

' $\mathrm{t}$ ' test analysis within the group $A$ shows that there is significant reduction in pain in individuals with Mechanical Low Back Pain, since the calculated ' $t$ ' value 14.1421 is greater than the table ' $t$ ' value 2.2621 at the $5 \%$ level of significance $(p<0.05)$, the null hypothesis is rejected.

\section{Group B (Pre-test and Post-test):}

' $\mathrm{t}$ ' test analysis within the group $B$ shows that there is significant reduction in pain in individuals with Mechanical Low Back Pain, since the calculated ' $\mathrm{t}$ ' value 12.0000 is greater than the table ' $t$ ' value 2.2621 at the $5 \%$ level of significance $(p<0.05)$, the null hypothesis is rejected.

\section{Independent ' $\mathrm{t}$ ' Test:}

\section{Pre-test Values (Group -A and Group-B):}

' $t$ ' test analysis for the pre-test values of group $A$ and group $B$ for pain is 0.6493 , which is less than the table ' $\mathrm{t}$ ' value 2.1009 at $5 \%$ level of significance, null hypothesis is accepted. It shows there is no significant difference in baseline value regarding pain between the two groups.

\section{Post-test Values (Group -A and Group-B):}

' $t$ ' test analysis for the post-test values of group A and group B for pain is 3.2478, which is greater than the table ' $\mathrm{t}$ ' value 2.1009 at $5 \%$ level of significance, null hypothesis is rejected. hence the individuals treated with McKenzie approach have shown greater reduction in pain than the individuals given taping.

\section{DISCUSSION}

As we all know that Mechanical Low Back Pain is a common problem affecting the daily functional activities of a large proportion of the population, it is important to relieve the problem effectively. Many physiotherapy interventional techniques are used in the management of this problem.

This study is to know the effect of McKenzie approach and Kinesio Taping technique in individuals with Mechanical Low Back Pain.

In this study 20 Mechanical Low Back Pain 
individuals were selected randomly and total parental sample was equally divided into two groups (Group A and Group B) Group A received McKenzie approach 3 sessions per week in 4 weeks. Group B received Kinesio Taping technique 3 sessions per week in 4 weeks.

Data was collected using Visual Analogue Scale for pain and Modified Oswestry Disability Index Scale for functional abilities. Statistical analysis was calculated by using ' $\mathrm{t}$ ' test with $95 \%$ level of confidence

In the $1950 \mathrm{~s}$ the New Zealand physical therapist, Robin McKenzie began to develop a system of assessment and treatment for mechanical back pain based on symptom response to spinal loading. In 1981 he published a book on mechanical diagnosis and therapy of the lumbar spine.

McKenzie developed 3 major classifications of mechanical back pain: postural, dysfunction and derangement syndromes. The definition of dysfunction syndrome includes overstretching of soft tissues that have been shortened or contain contracted scar tissue. Basically, McKenzie chose the term "dysfunction" instead of "adaptive shortening."

Dysfunction syndrome mechanical and symptomatic responses to loading behave as if adaptive shortening, loss of elasticity, scar tissue formation, etc., are restricting spinal movements. For dysfunction syndrome patients, symptom free movement is accomplished until the end range of a shortened structure is realized, at which point there is prohibition of further range accompanied by symptoms.

The goal is to remodel shortened tissue by frequently provoking the discomfort of loading at the restricted end range. Dysfunction syndrome patients tend to avoid their end range discomforts, perpetuating the condition.

McKenzie maintains that once nuclear material has escaped through the annular wall, the inherent hydrostatic mechanism is no longer intact,

McKenzie exercise increase endorphins and alter perception of pain perhaps by reducing anxiety and depression.
The McKenzie exercise centralize the pain in core back structures rather than treat pain, that is localized in a specific area, McKenzie exercise abolish their localized pain which can be acute or chronic [9].

The overall goal of this McKenzie exercise program is to reduce pain, develop the muscle support of their trunk and spine and to diminish stress to the intervertebral disc and other static stabilizers of the spine.

Schenk et al found a significant positive difference for pain and function (VAS, Oswestry Disability Index) outcomes for pre-post measures using McKenzie based directional preference exercise [10].

Kinesio Taping, developed by Kenzo Kase in early 70s, is a technique used in the clinical management of people with chronic low back pain. The tape, attached to the skin, is thinner and elastic than normal clinical tape. It can be stretched to $120-140 \%$ of its original length, producing mechanical restraint low and less restriction of mobility than conventional tape $[7,8]$.

Kenzo Kase, said that the therapeutic mechanisms of Kinesio Tape is: Improving muscle function by strengthened the weak muscles, Increasing blood and lymph circulation by removing tissue fluid, Reducing pain through neurological suppression, Repositioning possible subluxed joints by relieving abnormal muscle tension, helping to return the function of fascia and muscle (Kase et al., 1996) [7]. Increasing proprioception through increased stimulation to cutaneous mechanoreceptors.

Yoshida and Kahanov (2007) Kinesio taping on the lower trunk increased active lower trunk flexion range of motion in healthy subjects, although various mechanisms were postulated to explain this Taping led to great awareness and, greater muscular activation around the area during the treatment period. this have produced mild endurance training effect on the trunk musculature [11].

Paolini et al (2011) Stated that the people with chronic low back pain were randomly allocated to: Kinesio Taping of the lumbar spine changed every third day: 30 min of supervised exercise three times per week; or a combination of 
these two interventions. All groups showed reductions in pain and disability over the 4-week treatment period. Comparing betweengroup of final data show no statistically significant differences between groups. Suggesting that Kinesio Taping may have same acute effects as that of exercise for chronic low back pain, although more precise values are required [12].

Pain relief in taping group was believed to be because of suppression of pain fibers from the involved segment and also improving proprioception thereby correcting the faulty movements.

McKenzie approach increases endorphin, centralize the pain, and develop the muscular support of their trunk and spine, so it reduces pain and improves functional ability for Mechanical low back pain individuals.

In dysfunction syndrome there is restriction of spinal movements due to adaptive shortening and loss of elasticity of muscle.

Since the McKenzie approach centralizes pain and develops muscular support of trunk and spine and decreases stress on intervertebral disc. There is a greater pain relief and improvement in functional abilities of Mechanical low back pain individuals.

Hence the study concluded that, there was a significant improvement in both the groups, but the McKenzie approach group showed a greater improvement when compared to Kinesio taping technique group.

\section{Limitations:}

This study has been done with smaller number of subjects. Larger sample is recommended. This study was short term study and therefore to make the results more valid long term study should be done. There was no control group

\section{Suggestions:}

Only pain and functional capacity were studied. Further study can be done including other variables like strength and flexibility. Follow up assessment is needed to find out the long term effectiveness on pain and functional abilities. Future studies the exercises can be done under the Supervision of therapist.

\section{CONCLUSION}

Study was to evaluate the effects of McKenzie approach and taping technique in individual with Mechanical low back pain. The pain status was measured using Visual Analogue Scale and functional abilities was measured using Modified Oswestry Disability Index Scale. 20 subjects were taken from typical population and randomly divided into 2 groups Experimental group $A$ and Experimental group $B$ with 10 in each group. Experimental group $A$ was given McKenzie approach. Experimental group $\mathrm{B}$ was given Kinesio Taping. The values of pain and functional abilities was measured on the beginning of the treatment and end of the $4^{\text {th }}$ week. The result were analyzed using student ' $t$ ' test. The result showed there is significant difference between Experimental group $A$ and Experimental group $B$. Experimental group $A$ improved more than Experimental group $B$.

Thus as conclusion, the current study provides evidence that McKenzie approach is more effective in reducing pain and improving functional abilities in individuals with Mechanical Low Back.

\section{Conflicts of interest: None}

\section{REFERENCES}

[1]. Waddell G "The back pain revolution" Churchill Livingstone 1998.

[2]. Engers a jellama $P$, wensing $m$ vantulder $M$, Patient education for low back pain 20 Jan 2003 in Issue, 2003.

[3]. Arthur $\mathrm{H}$ White " conservative care of low back pain " Robert Anderson; 1994.

[4]. Cole and Herring (2003). Low Back Pain Hand Book. Honeleybelf. 150653493 1.3;27,6;71.

[5]. Jeffery D Boyling, Nigel Palastanga, Gwendolen A. Jull, Diane G. Lee, Gregory P. Grieve. Grieve's Modern Manual Therapy (the vertebral column); 1994: $2^{\text {nd }}$ edition: 753- 769.

[6]. Helen A Claire, Roger Adams and Christopher G Maher. A systemic review of efficacy of McKenzie therapy for spinal pain. Australian Journal of Physiotherapy; 2004;50: 209-216.

[7]. Kase K, Tatsuyuki H, Tomoko O. Development of kinesio tape. Kinesio taping perfect manual. Kinesio Taping Association 1996;6:117-118.

[8]. Kase K, Wallis J, Kase T (2003) Clinical therapeutics applications of the Kinesio Taping method. Tokyo : Ken Ikai Co Ltd.

[9]. Blumenthal, J. A.; Williams, R. S., Needels, T. L. Psychological Changes accompany aerobic exercise in healthy middle-aged adults. Psychosomatic Medicine, 1982;44;529-536. 
[10]. Schenk RJ, Jozefczyk C, Kopf A. A randomized trial comparing interventions in patients with lumbar posterior derangement. J Man Manip Ther. 2003;11(2):95-102.

[11]. Yoshida A, Kahanov $L$ to determine the effects of kinesio taping (KT) on trunk flexion, extension, and lateral flexion. Res Sports Med. 2007 Apr-Jun; 15(2):103-112.
[12]. Paolini M, Bernetti A, Fratocchi G, Mangone M, Parrinello L, Cooper MP. Kinesio Taping applied to lumbar muscles influences clinical and electromyographic characteristics in chronic low back pain patients. European Journal of Physical and Rehabilitation Medicine 2011;47:237-244.

How to cite this article: Manikandan A, David V Samuel, Mohammed Qasheesh, Senthilkumar Cennappan Bose. Effects of McKenzie Approach and Kinesio Taping Technique in Individuals with Mechanical Low Back Pain: A Comparative Study. Int J Physiother Res 2021;9(3):3809-3816. DOI: 10.16965/ijpr.2021.119 